\title{
Thermal Hydraulic Performance of Tight Lattice Bundle*
}

\author{
Yasushi YAMAMOTO**, Miyuki AKIBA**, Shinichi MOROOKA**, \\ Kenetsu SHIRAKAWA** and Nobuaki ABE** $^{* *}$
}

\begin{abstract}
Recently, the reduced moderation spectrum BWR has been studied. The fast neutron spectrum is obtained through triangular tight lattice fuel. However, there are few thermal hydraulic test data and thermal hydraulic correlation applicable to critical power prediction in such a tight lattice bundle. This study aims to enhance the database of the thermal hydraulic performance of the tight lattice bundle whose rod gap is about $1 \mathrm{~mm}$. Therefore, thermal hydraulic performance measurement tests of tight lattice bundles for the critical power, the pressure drop and the counter current flow limiting were performed. Moreover, the correlations to evaluate the thermal-hydraulic performance of the tight lattice bundle were developed.
\end{abstract}

Key Words: Tight Lattice Bundle, Thermal-Hydraulics, Critical Power, Pressure Drop, Post-BT, Counter Current Flow Limiting

\section{Introduction}

An innovative fuel cycle system concept named BARS (BWR with an Advanced Recycle System) has been proposed as a future fuel cycle option aiming at enhanced utilization of uranium resources and reduction of radioactive waste ${ }^{(1)-(4)}$. In BARS, the spent fuel from conventional light water reactors (LWRs) is recycled as a mixed oxide (MOX) fuel for the BWR core with a fast neutron spectrum through oxide dry-processing and vibropacking fuel fabrication as shown in Fig. 1. The fast neutron spectrum is obtained through triangular tight fuel lattice fuel as shown in Fig. 2. However, there are few thermal hydraulic test data and thermal hydraulic correlation applicable to critical power prediction in such a tight lattice bundle. This study aims to enhance the database of the thermal hydraulic performance of the tight lattice bundle whose rod gap is about $1 \mathrm{~mm}$.

In our previous study ${ }^{(5)}$, we reported that a critical power test that was performed with the tight lattice bundle and Arai's correlation ${ }^{(6)}$ could be applied for predicting critical power of the tight lattice bundle. However, the previous critical power test was performed with a longer heating length $(3.7 \mathrm{~m})$ than that of the BARS fuel. The BARS core consists of two heating length fuels ${ }^{(3)}$. One is a full length fuel whose heating length was designed to be $1.6 \mathrm{~m}$.

* Received 30th September, 2005 (No. 05-4184)

** Power and Industrial Systems R\&D Center, Toshiba Corporation, 8 Shinsugita-cho, Isogo-ku, Yokohama 2358523, Japan. E-mail: yasushi3.yamamoto@ toshiba.co.jp
The other is called the "streaming channel" whose heating length was designed to be $0.8 \mathrm{~m}$. Therefore, the thermalhydraulic tests were conducted to enhance the thermal-

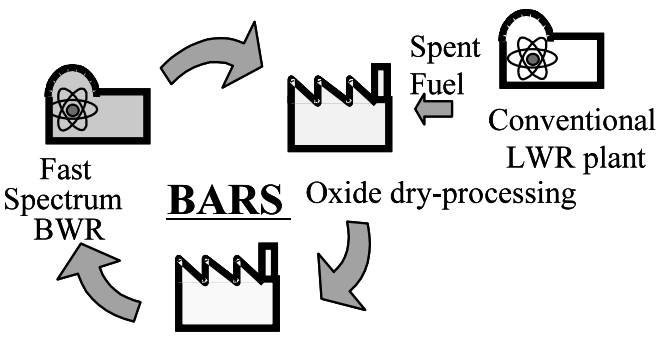

Vibro-packing fuel fabrication

Fig. 1 BARS concept

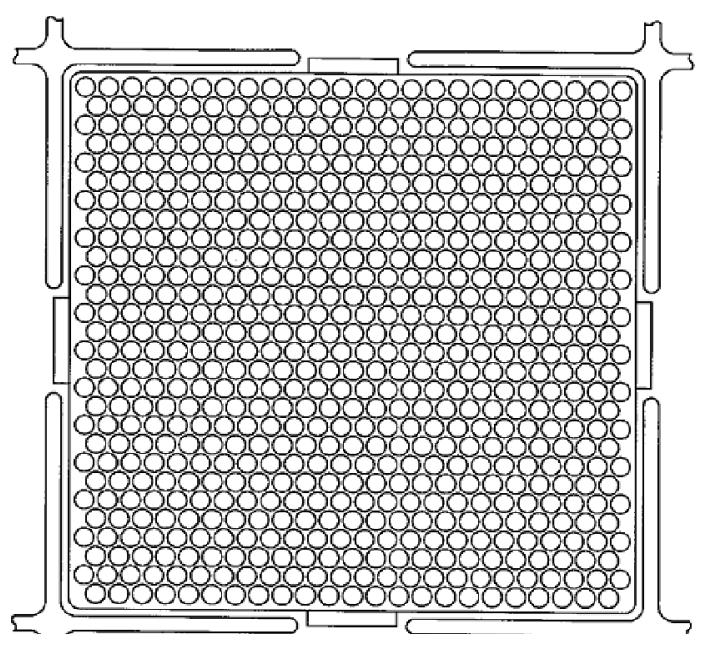

Fig. 2 Cross-sectional view of BARS fuel 
hydraulic database for the tight lattice bundle such as the critical power, pressure drop and counter current flow limiting (CCFL) characteristics, and to develop a more accurate correlation for predicting the thermal hydraulic performance of the tight lattice bundle.

\section{Thermal-Hydraulic Test}

\subsection{Critical power and pressure drop measure- ment test}

Two types of test bundle were manufactured. One was a 7-rod test bundle with a hexagonal channel box. The other was a 14-rod test bundle with a rectangular channel box.

The aim of the 7-rod bundle test was to survey the rod gap effect and heating length effect on the thermalhydraulic performance. Table 1 summarizes the test bundle geometry. Figure 3 shows a schematic view of the 7-rod test bundle. The test bundle consisted of header rods, honeycomb-type spacers and a hexagonal channel box. The stepped-cosine distribution was applied to the axial power distribution. The center rod peak distribution was also applied to radial power distribution. In the case of the short heating length, $0.8 \mathrm{~m}$, the upper $1 / 2$ of the heating region does not exist in Fig. 3. In actual partial length fuel, the axial power distribution also becomes the outlet peak. Therefore, the outlet peak distribution was applied. Figure 4 shows a photograph of the test bundle. Figure 5 shows an enlarged photograph of the honeycombtype spacer. The thickness and height of the spacer are $0.3 \mathrm{~mm}$ and $25 \mathrm{~mm}$, respectively.

The aim of the 14-rod bundle test was to check the ef-

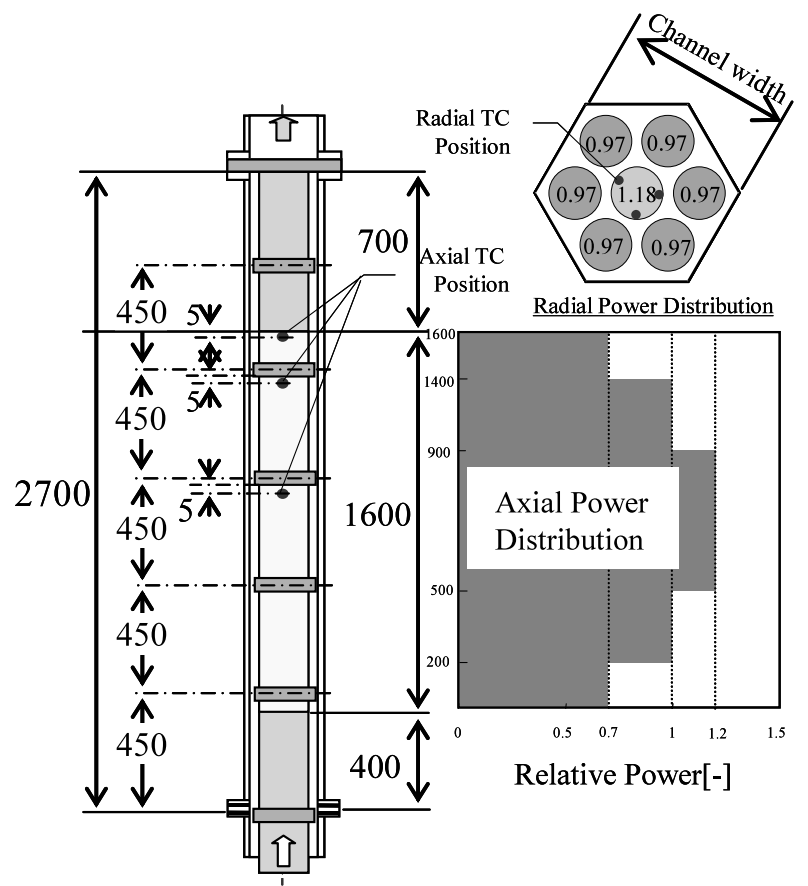

Fig. 3 Schematic view of 7-rod test bundle fect of radial power distribution on the thermal-hydraulic performance. Table 2 summarizes the test bundle geometry. The axial power distribution and spacer positions are the same as those of the 7-rod test whose heated length is $1.6 \mathrm{~m}$ as shown in Fig. 3. The two types of tests for the radial power distribution were performed as shown in Fig. 6 . One is the center peak distribution. The other is the side peak distribution.

Figure 7 shows the system diagram of the test facility. This test facility is usually called BEST (Toshiba BWR Experimental Loop for Stability and Transient test). This loop has the capability of testing under BWR operating

Table 1 Test bundle geometry (7-rod)

\begin{tabular}{|l|rrr|}
\hline Rod Gap [mm] & 0.8 & 1.3 & 1.8 \\
\hline Channel Width [mm] & 35.3 & 36.9 & 38.6 \\
Rod Dia. [mm] & 10.8 & 10.8 & 10.8 \\
Corner Radius [mm] & 5 & 4 & 3 \\
Flow Area [mm2] & 432 & 535 & 649 \\
Hydraulic Perimeter [mm] & 356 & 362 & 369 \\
Heated Perimeter [mm] & 237 & 237 & 237 \\
Heating Length [m] & 1.6 & $0.8,1.6$ & 1.6 \\
\hline
\end{tabular}

Table 2 Test bundle geometry (14-rod)

\begin{tabular}{|lc|}
\hline Rod Gap [mm] & 1.3 \\
Channel Width [mm] & $52.5 \times 49.8$ \\
Rod Dia. [mm] & 10.8 \\
Flow Area [mm2] & 1134 \\
Hydraulic Perimeter $[\mathrm{mm}]$ & 790 \\
Heated Perimeter $[\mathrm{mm}]$ & 475 \\
Heating Length & 1.6 \\
\hline
\end{tabular}

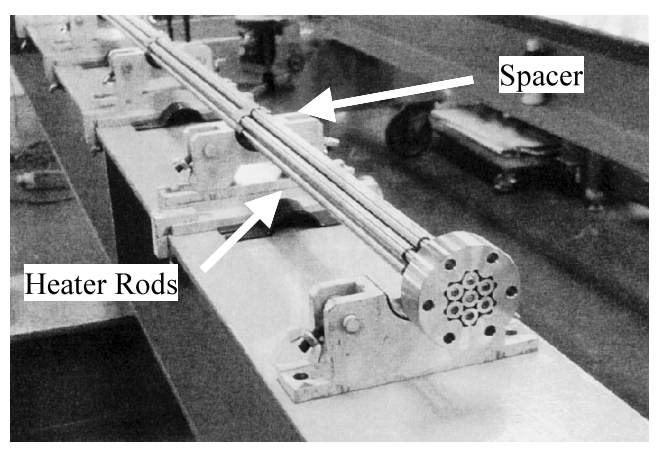

Fig. 4 Photograph of 7-rod test bundle

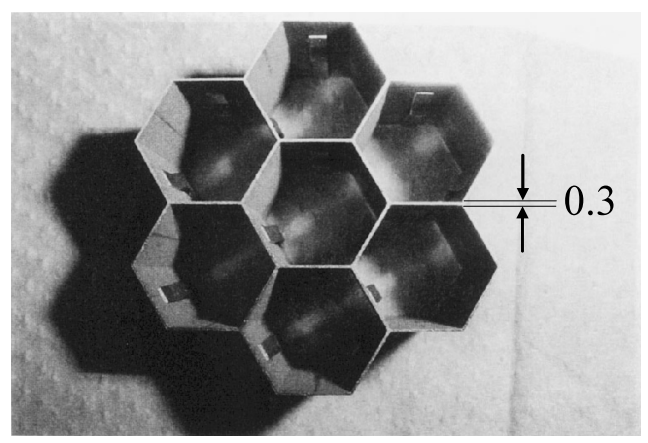

Fig. 5 Photograph of honeycomb-type spacer 


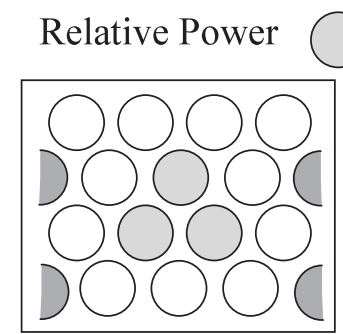

Center Peak
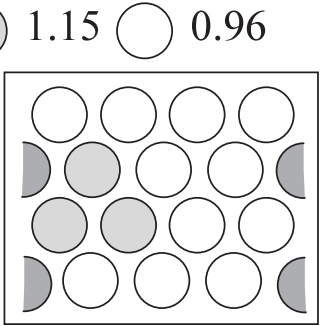

Side Peak
Fig. 6 Radial power distribution

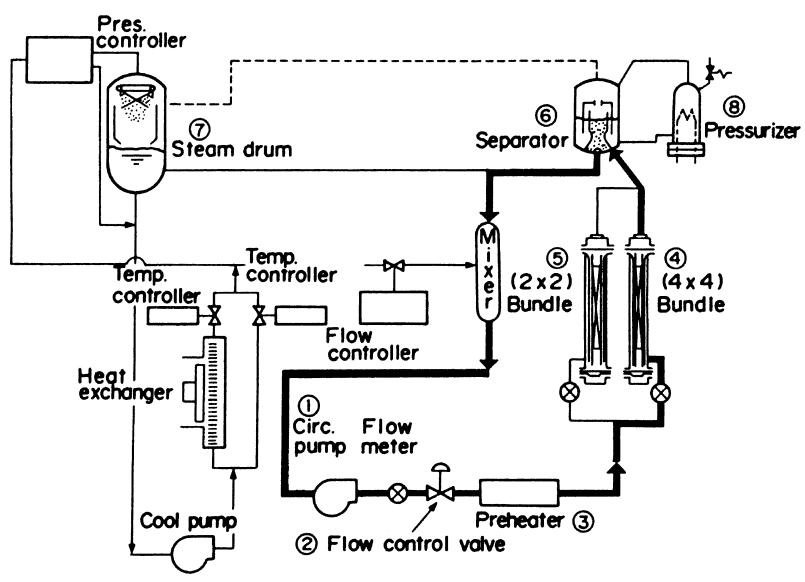

Fig. 7 Flow diagram of test facility (BEST Loop)

conditions. The measurement range and the precision of the flow condition are shown below.

Pressure: $0 \sim 11.8 \mathrm{MPa} \pm 0.5 \%$ (Pressure transmitter)

Temperature: $0 \sim 350^{\circ} \mathrm{C} \pm 0.5 \%$ (K-type thermocouple)

Flow rate: $0 \sim 15 \mathrm{~m}^{2} / \mathrm{h} \pm 0.5 \%$ (Venturi flow meter)

Power: $0 \sim 1.2 \mathrm{MW} \pm 0.5 \%$ (Direct current metering system)

In our test, pressure, inlet water temperature and flow rate were set to the programmed test conditions. Then, the bundle power was raised step by step for each small magnitude. Critical power was defined as the power when the rod surface temperature jumped by 14 centigrade from the temperature under nucleate boiling conditions. This definition was applied to the verification test of the thermalhydraulic design base reliability of BWR fuel assembly by Akiyama et al. ${ }^{(9)}$ The rod surface temperatures were measured by $0.5 \mathrm{~mm}$-in-diameter sheath-type thermocouples (K-type, JIS 0.4 class). Individual thermocouples are embedded in the rod surface as shown in Fig. 8.

Test conditions were as follows:

Pressure: $1 \sim 8 \mathrm{MPa}$

Mass flux: $500 \sim 2000 \mathrm{~kg} / \mathrm{m}^{2} \mathrm{~s}$

Inlet subcooling: $25 \sim 100 \mathrm{~kJ} / \mathrm{kg}$

\subsection{CCFL test}

In the tight lattice bundle, one of our concerns was that the spray water could not drain into the core at LOCA,

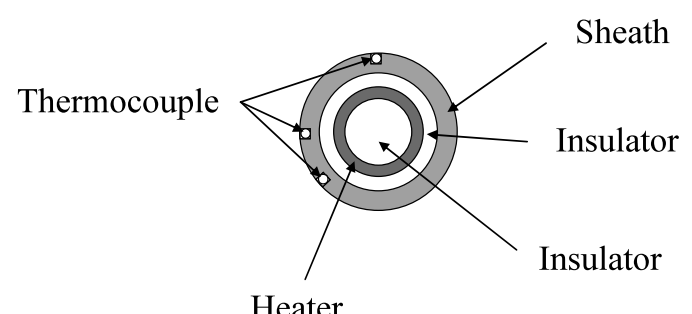

Fig. 8 Cross section of heater rod

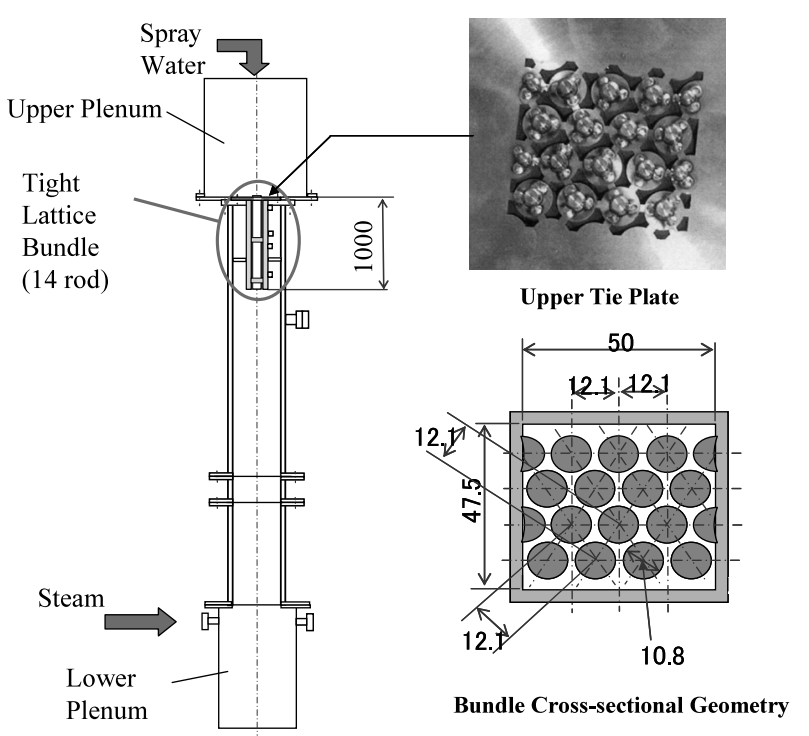

Fig. 9 CCFL test section

because the tight lattice bundle has a narrow flow channel. Therefore, the counter current flow limiting (CCFL) test of the tight lattice bundle was conducted. The test bundle consists of a14-rod bundle partially modeled BARS fuel bundle. CCFL occurred in the upper tie-plate because the flow area of the upper tie-plate is the smallest of the fuel assembly. Therefore, the upper tie-plate of the test bundle simulated half rods near the channel box, shown in Fig. 9. Test conditions were as follows:

Pressure: atmospheric

Steam Flow rate: $2 \sim 12.5 \times 10^{-3} \mathrm{~kg} / \mathrm{sec}$

The steam blew into the lower plenum. The flow rate of the falling water from the upper plenum was measured.

\section{Test Result}

\subsection{7-rod test}

The typical results of the steady-state critical power test results are shown in Figs. 10 and 11. Figure 10 shows the mass flux dependence on the critical power compared with different rod gap cases. The critical power results of the 1.8-mm gap test bundle were highest of all under the same mass flux condition. This result means the critical power depends on the rod gap. Figure 11 shows the heating length effect on the critical power. Although the heating length becomes $0.8 \mathrm{~m}$ from $1.6 \mathrm{~m}$, the critical power is larger than half of the critical power with a heating length 


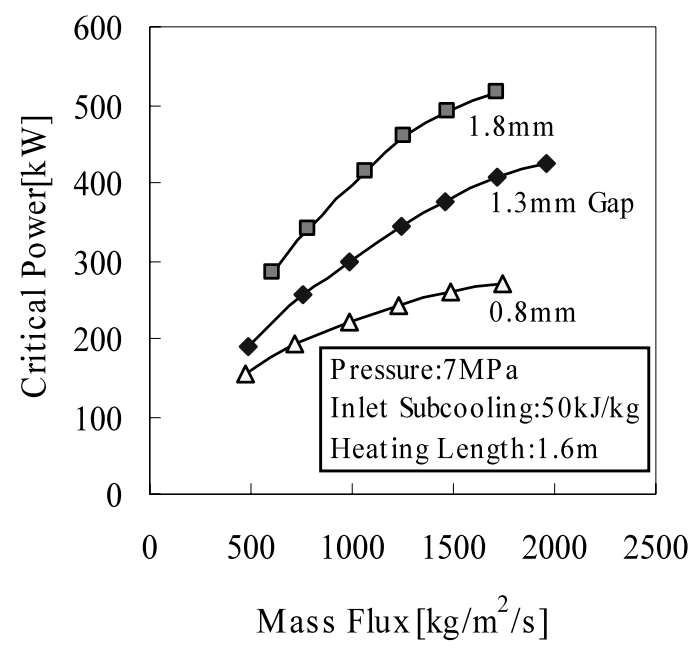

Fig. 10 Mass flux dependence on the critical power for different rod-gap cases

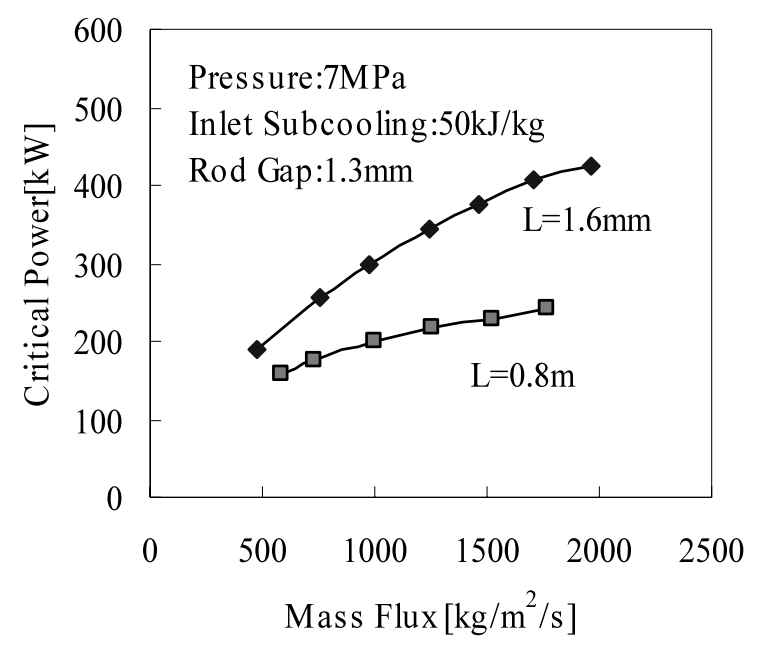

Fig. 11 Heating length (L) effect on the critical power

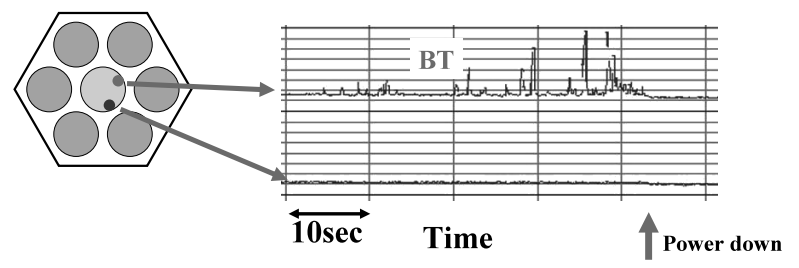

Fig. 12 Rod surface temperature behavior of the onset of boiling transition

$1.6 \mathrm{~m}$. It means that there is some thermal margin at the maximum heat flux position on the $1.6 \mathrm{~m}$ bundle, when $\mathrm{BT}$ is observed. In fact, BT is observed at the end of the heating region or just upstream of the most downstream spacer in the heating region on the $1.6 \mathrm{~m}$ bundle.

Figure 12 shows the rod surface temperature behavior of the onset of the boiling transition. The temperature intermittently jumped from the nucleate boiling temperature at the onset of the boiling transition. This behavior is the same as that of conventional BWR fuel. Therefore, it is assumed that the boiling transition mechanism is also the

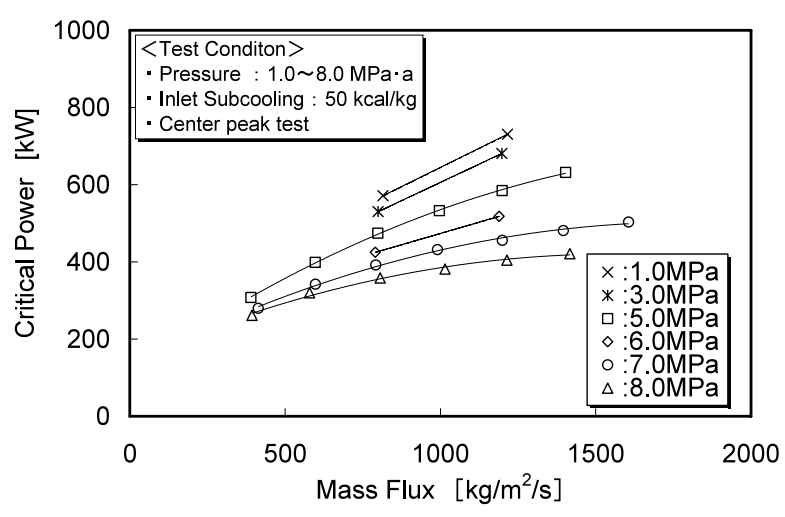

Fig. 13 Mass flux dependence on the critical power for different pressure cases

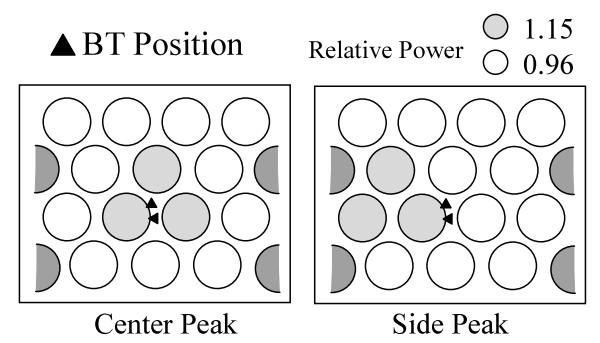

(a) BT position

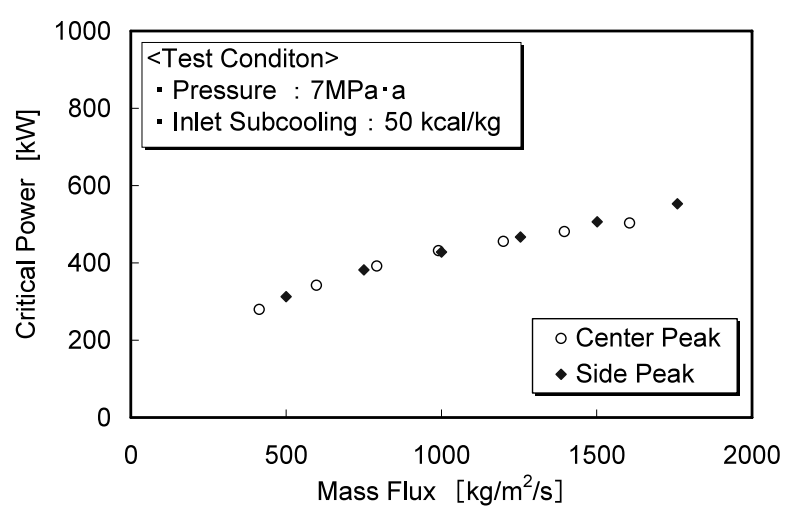

(b) Critical power measurement results

Fig. 14 BT position and mass flux dependence on the critical power of the center peak and side peak data

same.

\section{2 14-rod test}

The typical results of the steady-state critical power test results are shown in Figs. 13 and 14. Figure 13 shows the mass flux dependence on the critical power for different pressure cases in the center peak test. In conventional BWR fuel, the critical power has a maximum value between 4 and $6 \mathrm{MPa}^{(12)}$. However, in the tight lattice bundle, as the pressure becomes higher, the critical power decreases. Yamamoto et al. ${ }^{(7)}$ conducted a parametric survey to investigate which properties were dominant in the pressure effect on critical power by subchannel analysis. They found that vapor density increased critical power and surface tension and latent heat decreased critical power as the pressure increased. As the channel size becomes smaller, 
the surface tension effect becomes larger. Thus, this pressure dependence of critical power might be the result of surface tension effects. In the pressure dependence of the tight lattice bundle, further investigation is necessary. Figure 14 shows the position where the boiling transition observed and the mass flux dependence of critical power of the center peak test and the side peak test. The critical power difference was extremely small in Fig. 14 (b). The boiling transition (BT) was observed at the $\mathrm{T} / \mathrm{C}$ position facing the center subchannel of the channel center on both the test bundle of the center peak and side peak as shown in Fig. 14 (a). On the center peak test bundle, this BT position was the expected result. However, on the side peak test bundle, this position was an unexpected result. These results showed that the center subchannel of the channel center is significantly weak from the perspective of heat removal. This means that the heat removal performance would depend on the subchannel position in the cross section of the fuel channel.

\subsection{Post-BT test}

The post boiling transition tests under the transient condition were also performed by 7- and 14-rod test bundles. On the reduced moderation spectrum BWR, the void fraction-power coefficient is smaller than that of conventional BWR. Therefore, transient flow coast down is a harsh condition from the perspective of heat removal. Figure 15 shows the typical flow coast down test condition. Power down was delayed. In Fig. 16, the typical behavior of the rod surface temperature under the transient flow

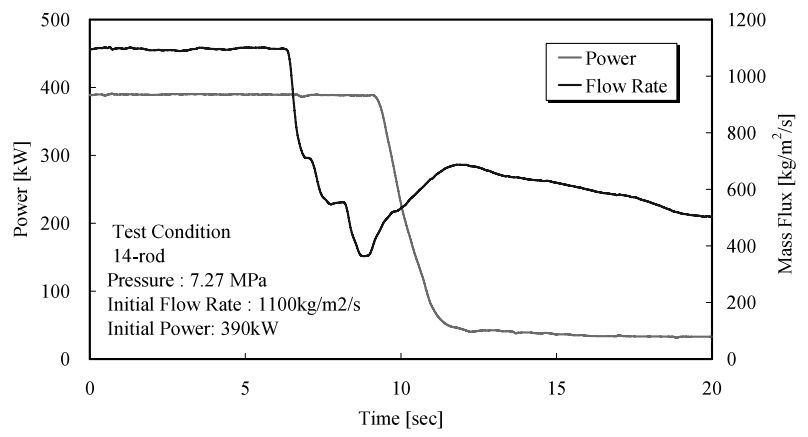

Fig. 15 Typical flow coast down test condition

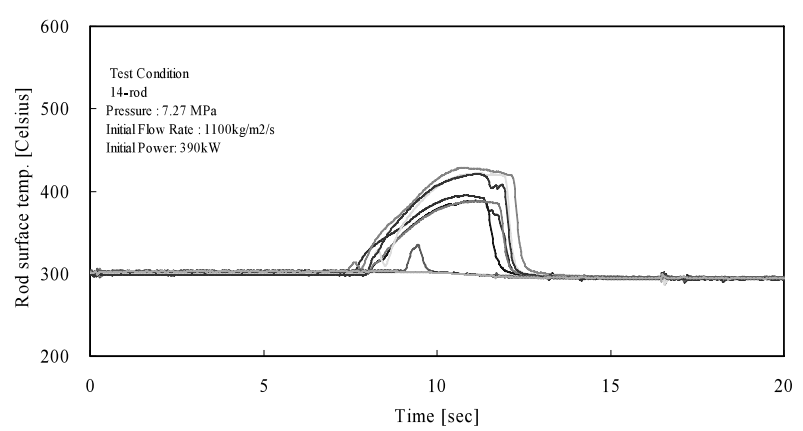

Fig. 16 Typical behavior of the rod surface temperature under the transient flow coast down coast down is shown. Though the boiling transition occurred, the rod surface temperature did not rise suddenly to a limit where the fuel rod was damaged. Then, the rod surface temperatures return to the nucleate boiling level by the power down.

\subsection{CCFL test}

Figure 17 shows the CCFL test results. The falling water flow rate decreases with the increase in the steam flow rate. This tendency is the same as conventional BWR fuel. The break line in Fig. 17 shows the falling water for conventional BWR fuel. Before the test, we considered that the falling water for the tight lattice bundle is extremely small. However, these results show the falling water flow rate is as almost the same as conventional fuel.

\section{Correlation}

\subsection{Critical power}

The critical quality-boiling length type correlation was selected, because it was hypothesized that the boiling transition mechanism was the same as conventional BWR fuel in section 3.1. The critical power correlation of conventional BWR fuel is exactly the critical quality-boiling length type correlation. In our previous study ${ }^{(5),(7)}$, we mentioned that Arai's correlation had applicability to the tight lattice bundle, and the consideration of the flow distribution in the rod bundle was necessary to predict the critical power accurately. A comparison of 7-rod test data and the calculated critical power using Arai's correlation is shown in Fig. 18.

First, the flow distribution effect was added based on Arai's correlation $^{(6)}$, as shown in Eq. (1)

$$
X_{c}=X_{c, \text { Arai }} \times F_{1}
$$

Here, $X_{c}$ : Critical quality, $X_{c, \text { Arai }}$ : Critical quality calculated by Arai's correlation, $F_{1}$ : the function of the flow distribution effects. The values of $1 / F_{1}$ were evaluated by $X_{c}$ calculated with the experimental data and $X_{c, \text { Arai }}$. In the same bundle, the dispersion of $1 / F_{1}$ was less then 0.1 . Therefore, $F_{1}$ was considered to be a function of bundle geometry. As a result, the $F_{1}$ fitted with the 7-rod test data of the $1.6 \mathrm{~m}$ heated length as shown in Eq. (2).

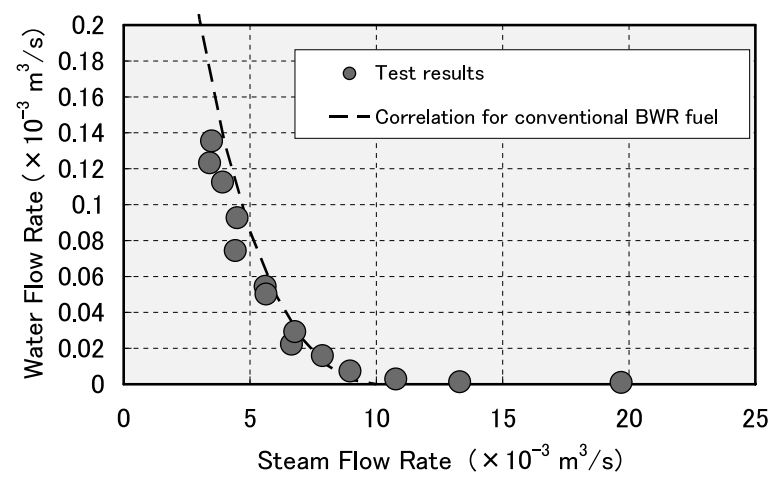

Fig. 17 CCFL test results 


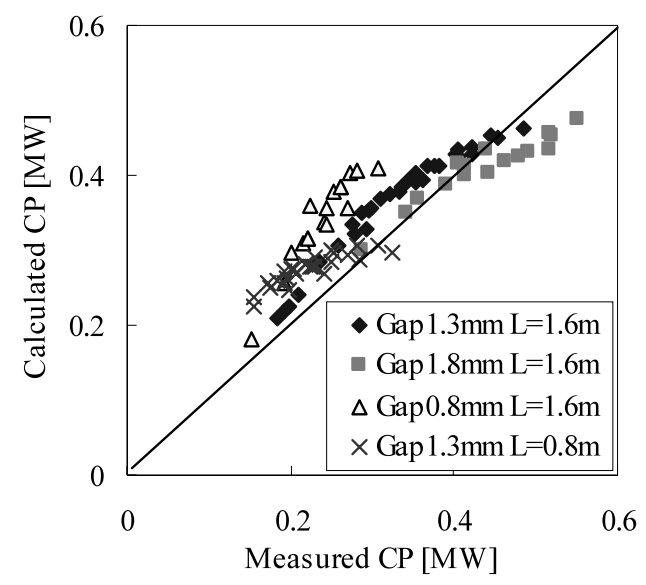

Fig. 18 7-rod critical power data versus calculated critical power with Arai's correlation

$$
F_{1}=1 / \max \left(1,-2.9876 D h_{\text {cent }} / D h+3.295\right)
$$

Here, the $D h_{\text {cent }}$ means the hydraulic diameter of the subchannel among the three rods. Dh means the bundle averaged hydraulic diameter. Thus, the coefficients of Arai's correlation were re-fitted with all the 7-rod test data to improve the critical power estimation of the short heating length fuel. The fitted correlation is shown below.

$$
\begin{aligned}
& X c_{1}=\frac{A_{1} \cdot L_{B}}{B_{1}+L_{B}} \cdot \frac{P_{h}}{P_{w}} R_{f}^{-1 / 2} \\
& X c_{2}=\frac{A_{2} \cdot L_{B}}{B_{2}+L_{B}} \cdot \frac{P_{h}}{P_{w}} R_{f}^{-1 / 2} \\
& A_{1}=1.0 \\
& A_{2}=a_{2} \cdot f p(P) / G^{m_{2}} \\
& B_{1}=b_{1} \cdot G^{m_{1}} \cdot D h^{n_{1}} h_{f g} / h(P) \\
& B_{2}=b_{2} \cdot G^{m_{3}} \cdot D h^{n_{1}} h_{f g} \\
& X c=\max \left(X c_{1}, X c_{2}\right) \times F_{1} \\
& a_{2}=1.297 \\
& b_{1}=2.616 e-7, \quad b_{2}=7.941 e-8 \\
& m_{1}=1.278, \quad m_{2}=0.1666, \quad m_{3}=1.23 \\
& n_{1}=1.5 \\
& p=10^{-5} P \\
& h(P)=-1.159+0.149 p \cdot e^{-0.019 p}+8.99 p /\left(10+p^{2}\right) \\
& f p(P)=0.7249+0.099 p \cdot e^{-0.032 p}
\end{aligned}
$$

$G$ : Mass flux $\left[\mathrm{kg} / \mathrm{m}^{2} / \mathrm{s}\right], L_{B}$ : Boiling length $[\mathrm{m}], P_{h}$ : Heated perimeter $[\mathrm{m}], P_{w}$ : Wetted Perimeter $[\mathrm{m}], R_{f}$ : Local peaking factor, $h_{f g}$ : Latent heat $[\mathrm{J} / \mathrm{kg}], P$ : Pressure [Pa]. The range of our test data that was used for fitting Eq. (3) is shown below.

Pressure: $5 \sim 8 \mathrm{MPa}$

Mass flux: $470 \sim 1960 \mathrm{~kg} / \mathrm{m}^{2} / \mathrm{s}$

$L_{B}: 0.8 \sim 1.6 \mathrm{~m}$

The calculated results with Eq. (3) are compared with Arai's correlation results in Fig. 19. Here, the averaged ECPR means the average of the experimental criti-

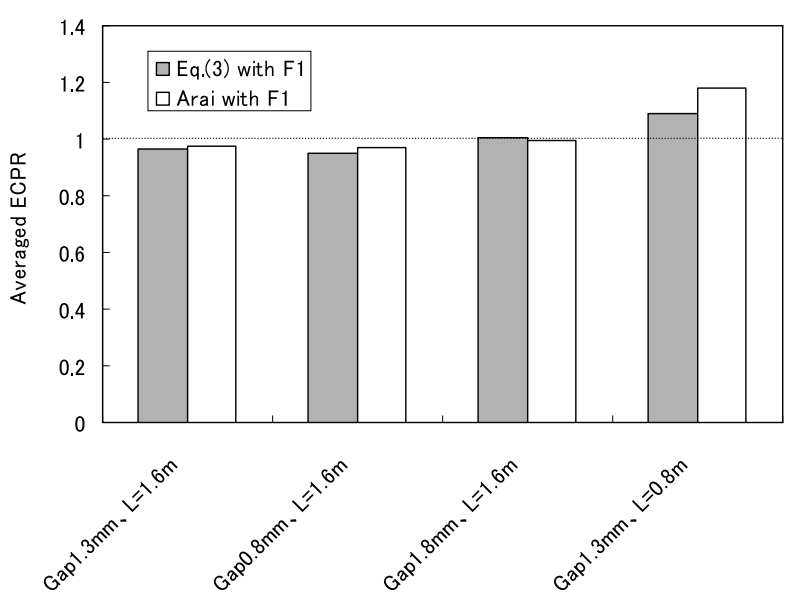

Fig. 19 Averaged ECPR results of Eq. (3) compared with Arai's correlation

cal power ratio $(=($ Calculated Critical Power $) /($ Measured Critical Power)). Thus, ECPR $=1$ means the calculated critical power equals the measured critical power. Figure 18 shows that the averaged EPCR of the short heating length bundle (Gap $1.3 \mathrm{~mm}, L=0.8 \mathrm{~m}$ ) was improved, and the other ECPRs were not changed and near 1.

Next, the radial peaking effect was added in Eq. (3) from the 14-rod test results. The 14-rod test results showed that the heat removal performance would depend on the subchannel position in the cross section of the fuel channel. To consider these test results, Eq. (3) was modified as Eq. (4).

$$
X c=\frac{A \cdot L_{B}}{B+L_{B}} \cdot \frac{P_{h}}{P_{w}} \frac{F_{1}}{R_{f}^{1 / 2}+\Delta R}
$$

$\Delta R$ is the coefficient of each rod position and is not a function of the other parameters, such as mass flux. $\Delta R s$ can be evaluated based on the test data and/or subchannel analysis results. In this study, $\Delta R s$ for the 14-rod bundle were evaluated with the subchannel analysis results under the BARS core rated condition (pressure: $7 \mathrm{MPa}$, mass flux: $1250 \mathrm{~kg} / \mathrm{m}^{2} / \mathrm{s}$, inlet subcooling: $50 \mathrm{~kJ} / \mathrm{kg}$ ). NASCA $^{(19)}$ for the subchannl analysis code was applied. In advance, the ratio of the experimental $X c$ to the calculated $X c$ with subchannel analysis was estimated by the 14-rod test results. At each rod position, the boiling transition was forcibly induced by increasing the rod peaking factor. Thus, the critical quality was estimated at each BT rod position in considering the ratio of the experimental $X c$ to the calculated $X c . \Delta R s$ can be calculated by Eq. (4). Figure 20 shows the evaluated results of $\Delta R s$ for the 14rod test bundle. It is noted that these $\Delta R s$ depend on the bundle geometry and can be applied to only this 14-rod test bundle. However, $\Delta R s$ for any bundle geometries can be evaluated accurately with only subchannel analysis in near future. Figure 21 shows the calculated critical power of the 7-rod and 14-rod data compared with the measured data. The calculated critical power is in good agreement 


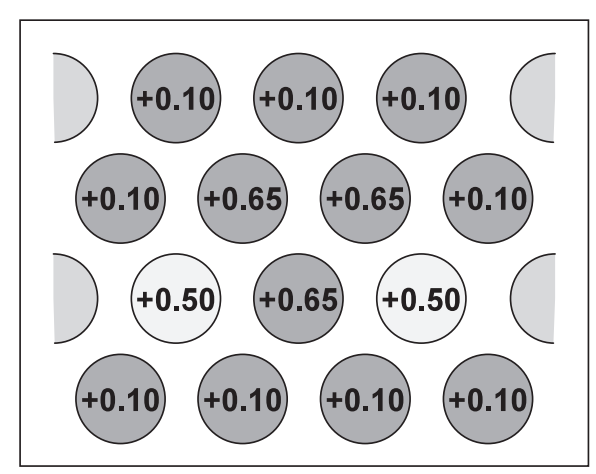

Fig. $20 \Delta R$ distribution of the 14-rod test bundle

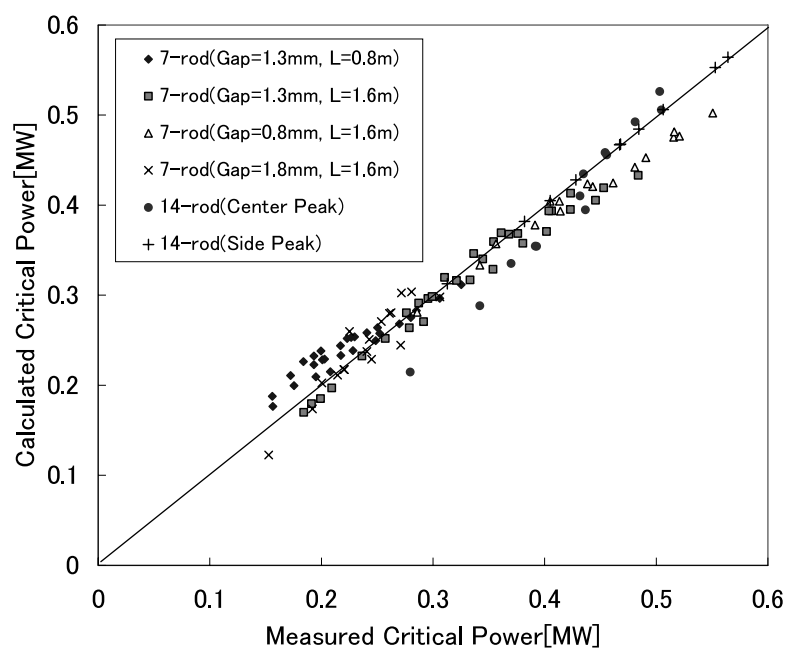

Fig. 21 Calculated critical power of 7-rod and 14-rod data compared with measured data

with the measured data. The averaged ECPR equals 0.99 . The standard deviation is $8 \%$. Since Eq. (2) equals 1 for the BAPL test bundle ${ }^{(18)}$ whose data is the basis of Arai's correlation and Eq. (3) mainly improved the critical power estimation of the short heating length fuel, it seems that the new correlation based on Arai's correlation has applicability to the BAPL test data on which Arai's correlation was based.

\subsection{Pressure drop}

The two-phase pressure drop $\triangle P_{T P H}$ was estimated by Akiyama's method ${ }^{(9)}$. In this study, it is evaluated with the following assumptions.

(1) Flow path is equivalent to a circular tube that has the hydraulic diameter of the fuel bundle.

(2) There is no flow distribution in the bundle.

Total pressure drop consists of each of the pressure loss components as shown below.

$$
\Delta P_{T P H}=\Delta P_{f}+\Delta P_{s p}+\Delta P_{h}+\Delta P_{a}
$$

We explained the estimated method of each of the pressure loss components of Eq. (5). Frictional pressure drop of two-phase flow $\Delta P_{f}$ is obtained by multiplying the single phase pressure loss with an empirical multiplier.

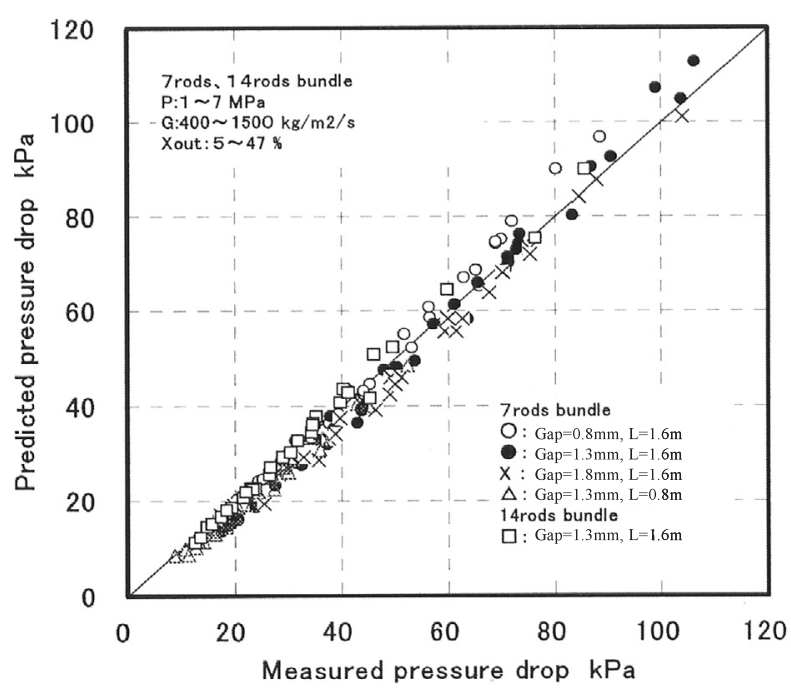

Fig. 22 Calculated pressure drop compared with measured data

$$
\Delta P_{f}=\frac{G^{2} L f_{L P}}{2 \rho_{g} D h} \Phi_{f}
$$

Two-phase friction loss multiplier $\Phi_{f}$ and single phase friction factor $f_{L P}$ are estimated by MartinelliNelson $^{(10)}$ and Blasius ${ }^{(11)}$. Spacer pressure loss is estimated by the following equation. A homogeneous multiplier for the spacer is used because it was found experimentally by Geiger ${ }^{(13)}$ and Lahey ${ }^{(12)}$ that a homogeneous multiplier does an excellent job of correlating the grid spacer data. The single-phase spacer loss coefficient $K s p$ is determined experimentally. The single-phase spacer loss coefficient $K s p$ was calculated by extracting spacer pressure loss estimated by Blasius ${ }^{(13)}$ and the head loss from the measured pressure drop for the single phase (power zero). $K s p$ for the $0.8,1.3,1.8 \mathrm{~mm}$ gap of the 7 rod bundle is $0.55,0.65$, and 0.75 , respectively. $K s p$ for the 14-rod bundle is 0.25 .

$$
\Delta P_{s p}=K s p \frac{G^{2}}{2 \rho_{f}}\left(1+\left(\frac{\rho_{f}}{\rho_{g}}-1\right) x\right)
$$

Head pressure loss was calculated by the following equation.

$$
\Delta P_{h}=\left[\alpha \rho_{g}+(1-\alpha) \rho_{f}\right] g L
$$

Void fraction and void departure were estimated by ZuberFindlay $^{(14)}$ and Saha-Zuber ${ }^{(15)}$. The subcooled boiling curve was estimated by Levy's profile fit model ${ }^{(16)}$.

Accelerated pressure loss was calculated by the following equation based on the separated flow model.

$$
\Delta P_{a}=G^{2}\left[\left\{\frac{x^{2}}{\alpha \rho_{g}}+\frac{(1-x)^{2}}{(1-\alpha) \rho_{f}}\right\}_{1}-\left\{\frac{x^{2}}{\alpha \rho_{g}}+\frac{(1-x)^{2}}{(1-\alpha) \rho_{f}}\right\}_{2}\right]
$$

Figure 22 shows the comparison with all data. The agreement between the calculated and measured pressure drop is good. Figure 23 slows the predicted ratio of each pressure loss component to total pressure loss. The ratio 


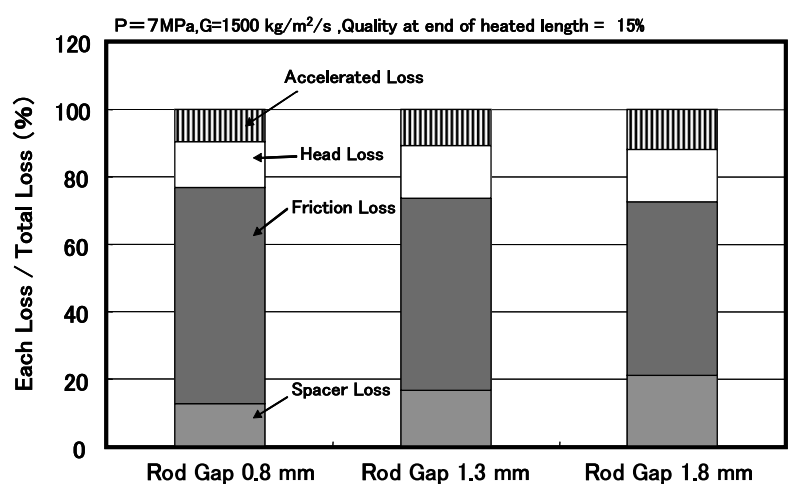

Fig. 23 Ratio of each pressure component to total loss

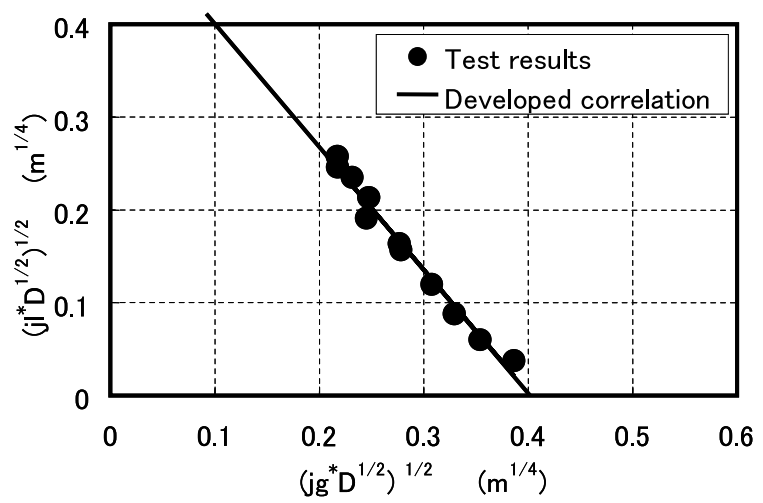

Fig. 24 Developed CCFL correlation compared with test data

of each pressure loss component changes with changes in bundle type, such as different spacer shape. In the case of this bundle, because the hydraulic diameter of the tight lattice bundle is small, the ratio of friction pressure loss is much larger.

\subsection{CCFL}

CCFL correlation for the tight lattice bundle was newly developed by the measured CCFL data of the tight lattice bundle. The developed correlation is shown below. This correlation was based on the Wallis-type correlation ${ }^{(17)}$ which is applied to conventional fuels. A comparison of our developed CCFL correlation and the test data is shown in Fig. 24.

$$
\begin{aligned}
& \sqrt{j_{g}^{*} D h^{1 / 2}}+0.754 \sqrt{j_{l}^{*} D h^{1 / 2}}=0.402 \\
& j_{g}^{*}=j_{g}\left[\frac{\rho_{g}}{g \cdot D h\left(\rho_{l}-\rho_{g}\right)}\right]^{1 / 2} \\
& j_{l}^{*}=j_{l}\left[\frac{\rho_{l}}{g \cdot D h\left(\rho_{l}-\rho_{g}\right)}\right]^{1 / 2} \\
& j_{g}=\frac{M_{g}}{A \cdot \rho_{g}}, \quad j_{l}=\frac{M_{l}}{A \cdot \rho_{l}}
\end{aligned}
$$

$j_{g}, j_{l}$ : Volumetric velocity of gas and liquid $[\mathrm{m} / \mathrm{s}], D_{h}$ : Hydraulic diameter $[\mathrm{m}], g$ : Acceleration due to gravity $\left[\mathrm{m} / \mathrm{s}^{2}\right], \rho_{g}, \rho_{l}$ : Density of gas and liquid $\left[\mathrm{kg} / \mathrm{m}^{3}\right], A$ : Flow area at upper tie plate $\left[\mathrm{m}^{2}\right], M$ : Mass flow rate $[\mathrm{kg} / \mathrm{s}]$.

\section{Conclusion}

To enhance the database of the thermal hydraulic performance of the tight lattice bundle, thermal hydraulic performance measurement tests of the tight lattice bundle for the critical power, the pressure drop and the counter current flow limiting were performed. Moreover, the correlations or method to evaluate the thermal hydraulic performance of the tight lattice bundle were developed.

The critical power correlation for the tight lattice bundle was developed based on Arai's correlation, which was the critical quality-boiling length type correlation. The flow distribution effect, $F_{1}$, and $\Delta R$ were added to Arai's correlation. Moreover, the coefficients of the correlation were modified from Arai's original correlation. The calculated critical power agreed well with the measured data within $8 \%$. The pressure drop estimation method was also studied and proposed. Our proposed method can estimate the pressure drop of the tight lattice bundle. Moreover, CCFL correlation for the tight lattice bundle was newly developed by the measured CCFL data of the tight lattice bundle. Consequently, we can provide the correlations and method to evaluate the important thermal-hydraulic performance of the tight lattice core, the minimum critical power ratio, pressure drop and the spray water behavior in LOCA.

\section{Acknowledgment}

This project is funded by the Institute of Applied Energy (IAE), Ministry of Economy, Trade and Industry (METI), Japan.

\section{References}

( 1 ) Yokoyama, T., Yoshioka, R. and Sakashita, Y., Study on Breeding Characteristics of Fast Spectrum BWR, International Conference on the Physics of Nuclear Science and Technology, Islandia Marriott Long Island, NY, (1998), pp.1679-1684.

( 2 ) Sakashita, Y., Yokoyama, T. and Tsuboi, Y., Core Characteristics of Breeding BWR for BARS (BWR with Advanced Recycle System), 7th International Conference on Nuclear Engineering (ICONE-7), Tokyo, (1999).

( 3 ) Yamaoka, M., Yamamoto, Y., Abe, N., Hiraiwa, K. and Yokoyama, T., Study on Fast Spectrum BWR Core for Actinide Recycle, 9th International Conference on $\mathrm{Nu}$ clear Engineering (ICONE-9), Nice, (2001).

(4) Hiraiwa, K., Yamamoto, Y., Morooka, S., Yamaoka, M., Abe, N., Mitsuhashi, I., Mimatsu, J. and Inoue, A., Study on BWR with Advanced Recycle System (BARS), International Congress on Advanced Nuclear Power Plants (ICAPP), Hollywood, Florida, (2002).

( 5 ) Yamamoto, Y., Morooka, S., Arai, K. and Shirakawa, K., Critical Power Performance of the Tight Lattice Bundle, Trans. At. Energy Soc. Japan, (in Japanese), Vol.1, No.3 (2002), pp.282-288. 
(6 ) Arai, K., Tsunoyama, S., Yokobori, S. and Yoshimura, K., Critical Power Characteristics of a High Conversion Boiling Water Reactor, IAEA Technical Committee on Technical and Economical Aspects of High Converters, Germany, (1990).

( 7 ) Yamamoto, Y., Mitsutake, T., Morooka, S. and Yoshioka, R., Critical Power Dependency on Pressure, The 3rd International Seminar on Subchannel Analysis, Stockholm, (1995).

( 8 ) Yamamoto, Y., Hiraiwa, K., Morooka, S. and Abe, N., Critical Power Performance of Tight Lattice Bundle, JSME Int. J., Ser.B, Vol.47, No.2 (2004), pp.344-350.

( 9 ) Akiyama, M., Inoue, A., Oishi, M., Aoki, T., Kagawa, T., Yoshimura, K., Ishizuka, T., Morooka, S., Hamada, J., Hoshide, A., Kojima, A., Terasaka, H., Mitsutake, T. and Yoshimoto, Y., Verification Test on ThermalHydraulic Design Base Reliability of BWR Fuel Assembly, J. At. Energy Soc. Japan, (in Japanese), Vol.31, No.2 (1989), pp.280-295.

(10) Martinelli, R.C. and Nelson, D.B., Prediction of Pressure Drop during Forced Circulation Boiling of Water, Trans. ASME, Vol.70 (1948), pp.695-702.

(11) Blasius, H., Forsh. Geb. Ing-Wes., Vol.131 (1913).

(12) Lahey, R.T., Jr. and Moody, F.J., Thermal-Hydraulic of a Boiling Water Nuclear Reactor, (1993), ANS.

(13) Geiger, G.E., Sudden Contraction Losses in Single-and
Two-Phase Flow, Ph.D Thesis, University of Pittsburg, (1964).

(14) Zuber, N. and Findlay, J.A., Average Volumetric Concentration in Two-Phase Flow System, J. Heat Transfer, Vol.87 (1965), pp.453-468.

(15) Saha, P. and Zuber, N., Point of Net Vapor Generation and Vapor Void Fraction in Subcooled Boiling, Proc. Fifth Int. Heat Transfer Conf., Vol.IV (1974).

(16) Levy, S., Force Convection Subcooled BoilingPrediction of Vapor Volumetric Fraction, GEAP-5157, (1964).

(17) Wallis, G.B., One-Dimensional Two-Phase Flow, (1969), McGraw-Hill.

(18) LeTourneau, B.W., Peterson, A.C., Coeling, K.J., Gavin, M.E. and Green, S.J., Critical Heat Flux and Pressure Drop Tests with Parallel Upflow of High Pressure Water in Bundles of Twenty 0.25- and 0.28Inch Diameter Rods (LWBR Development Program), WAPD-TM-1013, (1975).

(19) Ninokata, H., Anegawa, T., Sou, A., Nishida, K., Yamamoto, Y. and Kusuno, S., Development of the NASCA Code for Predicting Transient BT Phenomena in BWR Rod Bundles, Proc. OECD/NEA Workshop on Advanced Thermal-Hydraulic and Neutronic Codes: Current and Future Applications, Barcelona, April, (2000). 